\title{
Stability of Precipitates in Zirconium Alloys under Self-ion Irradiation
}

\author{
Xu Wang ${ }^{1,2}$, Mengqiao Zhao ${ }^{2}$, Feifei Zhang ${ }^{1,2}$, Lumin Wang ${ }^{2,1}$ \\ ${ }^{1 .}$ Collge of Energy, Xiamen University, Xiamen, Fujian 361102, China \\ 2. Department of Nuclear Engineering and Radiological Science, University of Michigan, Ann Arbor, \\ Michigan 48109, United States
}

Zirconium alloys are widely used in nuclear power reactors as fuel cladding and core structure materials due to their low neutron capture cross section, good corrosion resistance and mechanical strength. To meet the requirement of high burnup of the nuclear fuel, new generation $\mathrm{Nb}$-containing zirconium alloys, such as M5, E110, E635 and Zirlo, were developed. Many ion and neutron irradiation experiments have been conducted on zirconium alloys to evaluate their radiation resistance [1,2]. The stability of the precipitates in the zirconium alloys is one of the most important concerns because it is believed to cause an accelerated rate of uniform corrosion besides other negative effects.

The material used in this study is zirconium based ally containing small amounts of $\mathrm{Fe}$ and $\mathrm{Nb}$. The samples were irradiated to $4.55 \times 10^{15} \mathrm{Zr}^{++} / \mathrm{cm}^{2}$ (20 dpa at the damage peak) using $3 \mathrm{MeV} \mathrm{Zr}^{++}$with a defocused beam in the Ion Beam Laboratory at Texas A\&M University, using a 1.7 MV Tandetron accelerator. The irradiations were conducted at $320^{\circ} \mathrm{C}, 360^{\circ} \mathrm{C}$ and $400^{\circ} \mathrm{C}$, respectively. Cross-section TEM samples were prepared by focused ion beam (FIB) lift-out method using a FEI Helios 650 NanolabDualbeam FIB. Scanning transmission electron microscopy (STEM) was conducted using a JEOL 2100 spherical aberration (Cs)-corrected high resolution STEM operated at $200 \mathrm{keV}$. TEM analysis and characterization were conducted using a JEOL 3100R05 double Cs-Corrected TEM. All the electron microscopy and sample preparation were conducted at University of Michigan Electron Microbeam Analysis Laboratory (EMAL).

Fig. 1 shows the HAADF, BF STEM images and EDS mapping of as received zirconium alloy. Precipitates are shown as black dots in the BF-STEM image (Fig.1b), and as white dots in HAADF image due to the higher mass of the main components. EDS mapping indicates that $\mathrm{Nb}$ and $\mathrm{Fe}$ are enriched in precipitates. $\mathrm{Hcp} \mathrm{Zr}(\mathrm{Cr}, \mathrm{Fe})_{2}$ and fcc $\mathrm{ZrFe}{ }_{2}$ laves phase are two types of precipitates which were commonly reported in zirconium alloys without $\mathrm{Nb}$, such as $\mathrm{Zr}$-4. In $\mathrm{Zr}-\mathrm{Nb}$-Fe ternary system, two Laves phases $\left(\mathrm{Zr}(\mathrm{Nb}, \mathrm{Fe})_{2}\right.$ and $\left.(\mathrm{Zr}, \mathrm{Nb}) \mathrm{Fe}_{2}\right)$, fcc $(\mathrm{ZrNb})_{2} \mathrm{Fe}$ intermetallic and two bec solid solutions $(\beta-\mathrm{Zr}$ and $\beta-\mathrm{Nb})$ were reported [3]. HRTEM images and corresponding FFT images of precipitates in three different zone axes are shown in Fig.2. According to these images, the precipitates are identified as bcc $\beta$ - $\mathrm{Zr}$ phase with lattice parameter $\mathrm{a}=0.35 \mathrm{~nm}$. Fig. $3 \mathrm{a}$ is a HRTEM images of the boundary of precipitate and matrix in the sample irradiated to $15 \mathrm{dpa}$ at $320^{\circ} \mathrm{C}$. It is clear that the precipitate is disordered while the matrix remains crystal. The inset is the corresponding selected-area electron diffraction (SAED) pattern showing that the precipitate has become amorphous after ion irradiation. Fig. $3 \mathrm{~b}$ and $3 \mathrm{c}$ are HRTEM images of samples irradiated at $360{ }^{\circ} \mathrm{C}$ and 400 ${ }^{\circ} \mathrm{C}$ respectively. It is apparent that the crystal structure of precipitates survived the irradiation at $360{ }^{\circ} \mathrm{C}$ and $400{ }^{\circ} \mathrm{C}$. To sum up, the amorphization of $\mathrm{Nb}$ enriched precipitates in the zirconium alloy were observed after self-ion irradiation to $20 \mathrm{dpa}$ at temperature lower than $360^{\circ} \mathrm{C}$.

\section{References:}

[1] H.H. Shen, S.M. Peng, X.S. Zhou, Chin.Phys. B 23(3) (2014), p. 036102.

[2] R.W. Gilbert, M. Griffiths, G.J.C. Carpenter, J. Nucl. Mater. 135 (1985), p. 265.

[3] C. Ramos, C. Saragovi, M.S. Granovsky, J. Nucl. Mater. 366 (2007), p. 198.

[4] This research is supported by China General Nuclear Power Group. 


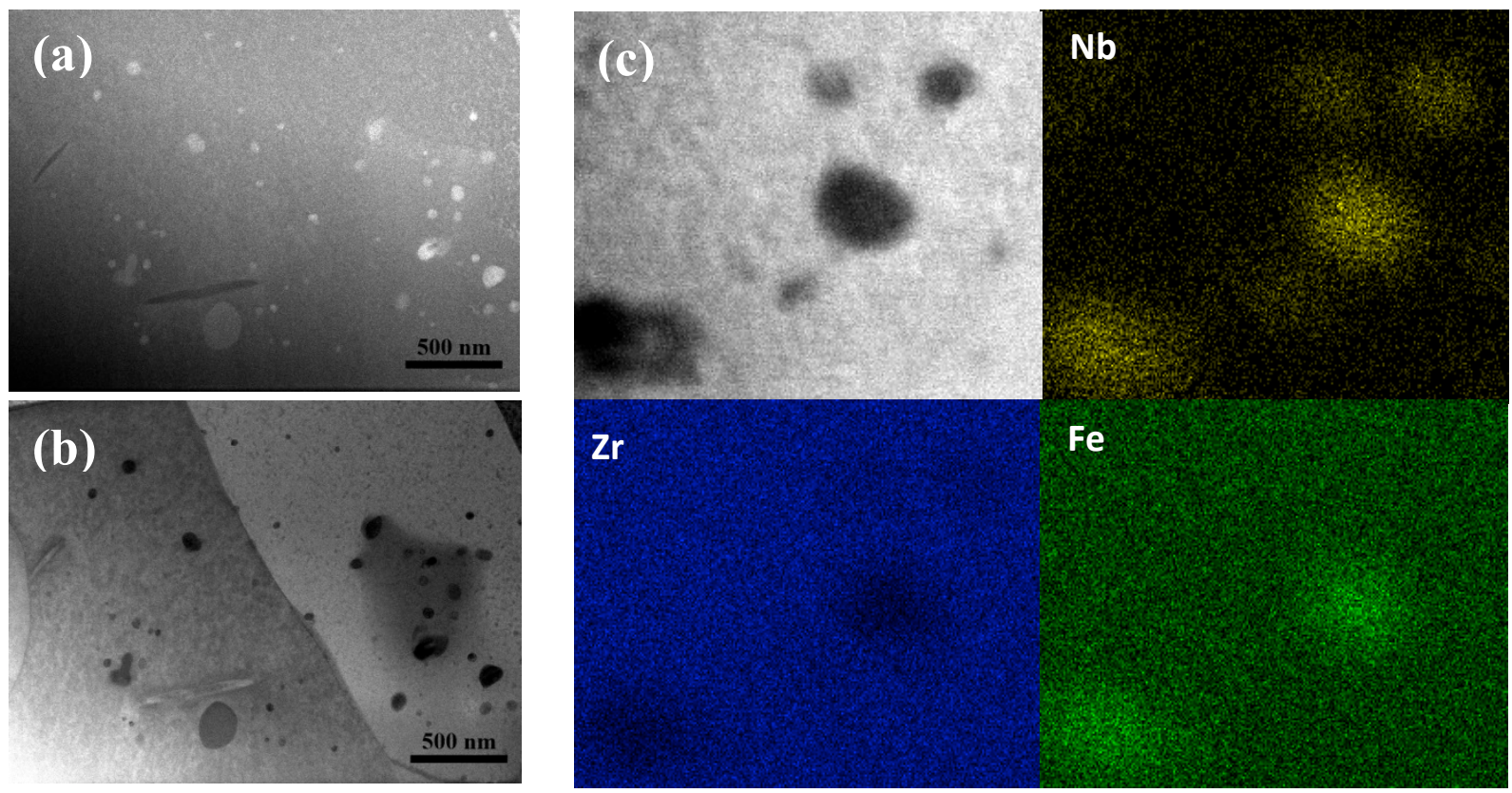

Fig. 1. (a) HAADF STEM images and (b) BF STEM images of unirradiated zirconium alloy; (c) EDS mapping shows $\mathrm{Nb}$ and $\mathrm{Fe}$ are enriched in precipitates.
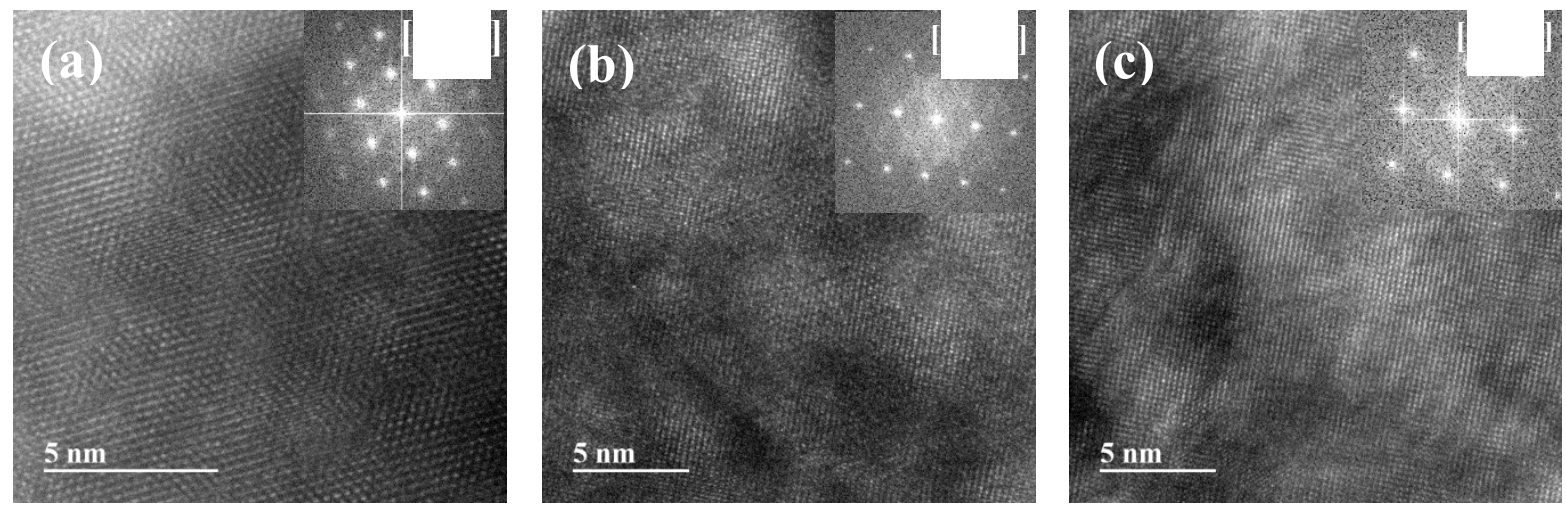

Fig. 2. HRTEM images and corresponding FFT images (inset) of precipitates in different zone axes, (a) [111]; (b) [011]; (c) [001]

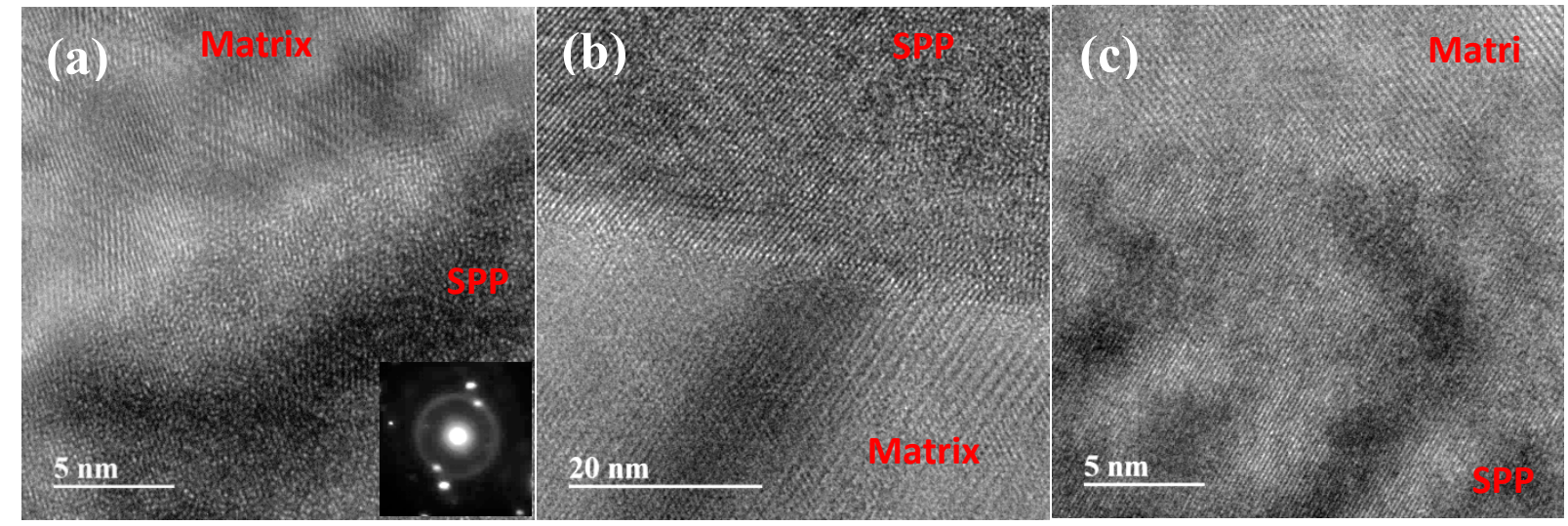

Fig. 3. HRTEM images from the boundary of precipitates and matrix of the samples irradiated up to $20 \mathrm{dpa}$ at (a) $320^{\circ} \mathrm{C}$, (b) $360{ }^{\circ} \mathrm{C}$ and (c) $400{ }^{\circ} \mathrm{C}$. 